\title{
Tuberculosis contact investigation results among paediatric contacts in low-incidence settings in Finland
}

\author{
Antti Kontturi $^{1,2}$ (D) Satu Kekomäki ${ }^{2} \cdot$ Eeva Ruotsalainen $^{3} \cdot$ Eeva Salo $^{2}$ \\ Received: 22 December 2020 / Revised: 8 February 2021 / Accepted: 17 February 2021 / Published online: 2 March 2021 \\ (C) The Author(s) 2021
}

\begin{abstract}
Tuberculosis (TB) risk is highest immediately after primary infection, and young children are vulnerable to rapid and severe TB disease. Contact tracing should identify infected children rapidly and simultaneously target resources effectively. We conducted a retrospective review of the paediatric TB contact tracing results in the Hospital District of Helsinki and Uusimaa from 2012 to 2016 and identified risk factors for TB disease or infection. Altogether, 121 index cases had 526 paediatric contacts of whom 34 were diagnosed with TB disease or infection. The maximum delay until first contact investigation visit among the household contacts under 5 years of age with either TB disease or infection was 7 days. The yield for TB disease or infection was $4.6 \%$ and $12.8 \%$ for household contacts, $0.5 \%$ and $0 \%$ for contacts exposed in a congregate setting and $1.4 \%$ and $5.0 \%$ for other contacts, respectively. Contacts born in a TB endemic country (aOR 3.07, 95\% CI 1.10-8.57), with household exposure (aOR 2.96, 95\% CI 1.33-6.58) or a sputum smear positive index case (aOR 3.96, 95\% CI 1.20-13.03) were more likely to have TB disease or infection.

Conclusions: Prompt TB investigations and early diagnosis can be achieved with a well-organised contact tracing structure. The risk for TB infection or disease was higher among contacts with household exposure, a sputum smear positive index case or born in a TB endemic country. Large-scale investigations among children exposed in congregate settings can result in a very low yield and should be cautiously targeted.
\end{abstract}

What is Known:

- Vulnerable young children are a high priority in contact tracing and should be evaluated as soon as possible after TB exposure

What is New:

- Prompt investigations for paediatric TB contacts and early diagnosis of infected children can be achieved with a well-organised contact tracing structure

- Large-scale investigations among children exposed in congregate settings can result in a very low yield and should be cautiously targeted

Keywords Tuberculosis $\cdot$ Vulnerable young children $\cdot$ Paediatric TB contact tracing

Communicated by Nicole Ritz

Antti Kontturi

antti.kontturi@helsinki.fi

Satu Kekomäki

satu.kekomaki@hus.fi

Eeva Ruotsalainen

eeva.ruotsalainen@hus.fi

Eeva Salo

eevasalo@dlc.fi

1 Doctoral Programme in Population Health, University of Helsinki, Helsinki, Finland

2 Department of Pediatrics, Children's Hospital, University of Helsinki and Helsinki University Hospital, Helsinki, Finland

3 Division of Infectious Diseases, Inflammation Center, Helsinki University Hospital, Helsinki, Finland

\section{Introduction}

In Europe, highly infectious pulmonary TB (pTB) cases are concentrating to the working age immigrant population and TB prevention remains a major public health concern [1]. Young children are especially vulnerable and eventually 30 $80 \%$ of children with household exposure are infected with TB $[2,3]$. Without preventive treatment, children under 5 years of age are especially prone to progression from TB infection to disease, and the risk is highest immediately after primary infection $[4,5]$.

Contact tracing is an imperative part of TB control [6]. Capturing and treating recently acquired infections decreases the pool of future TB cases especially in low-incidence countries $[7,8]$. Because young age is a pivotal risk factor, TB yield 
among the youngest exposed provides important insight into the swiftness of contact tracing. Childhood TB infections are also sentinel events indicating ongoing transmission in the community but national TB registers capture only active TB [9]. Large-scale investigations can result in low yield and resources should be targeted effectively [10]. Recent publications concerning paediatric contact investigations in a low-incidence setting in Europe are scarce and few address the timing of investigations [4].

Our aim was to evaluate the contact tracing results and identify risk factors for TB disease or infection among children exposed to TB in the Hospital District of Helsinki and Uusimaa (HUS) area in Finland.

\section{Materials and methods}

\section{Study population}

We conducted a retrospective cohort study and reviewed the records of all paediatric contacts exposed to TB in the HUS area from 2012 to 2016 and their respective index cases. HUS includes 24 member municipalities with approximately 1.7 million residents [11]. Currently, approximately $250 \mathrm{~TB}$ cases emerge annually in Finland. Of these, a third occur in the HUS area [12]. All TB contact tracing in the area is supervised by the HUS epidemiological unit and all paediatric TB patients are treated in the same public tertiary hospital.

We identified the index cases and contacts from the epidemiological unit records and collected retrospective data concerning the patient characteristics, exposure, investigations and results from the medical records. Contacts under the age of 16 at the time of exposure were listed as paediatric. Older siblings aged 16 to 17 were included if they underwent investigations together with their younger siblings in the paediatric clinic. We excluded contacts who were exposed outside the HUS area or deemed unexposed at the first contact investigation visit (i.e. no contact with the index case).

\section{Ethics statement}

The ethics approval for the study was given by the Research Ethical Committee of the HUS.

\section{Definitions}

The exposed children were classified retrospectively from the epidemiological unit records and medical records. The exact duration of exposure was not retrospectively available; however, the national TB program in Finland includes national guidelines for $\mathrm{TB}$ contact tracing that dictates contacts who are included in contact investigations. The guidelines in place during the whole retrospective study period were published in
2011 by the Finnish Institute for Health and Welfare (THL). Briefly, in the guidelines, an index case is the initially identified case of new or recurrent TB. An index case with a sputum smear-positive or cavitary pTB or smear-positive secreting extrapulmonary TB is considered highly infectious. Primary investigations are recommended to all who have been exposed to highly infectious index case in the same household or enclosed space over eight cumulative hours. Additionally, primary investigations are recommended to children under 5 years of age who have been exposed to any pTB index case in the same household or enclosed space over eight cumulative hours, or to a highly infectious index case repeatedly in an enclosed space for less than eight cumulative hours. Based on the records, we classified the exposure of the children as household (i.e. exposure in the same household), congregate (i.e. exposure in a school or reception centre) or other (i.e. all other contacts included in contact investigations).

The outcome was classified as diagnosed by the treating physician at the last contact investigation visit: TB disease (i.e. confirmed or clinically diagnosed case of TB disease), TB infection (i.e. diagnosed TB infection without signs of disease), no infection or unknown (i.e. incomplete contact investigations or data unavailable). We also reviewed the medical records of the exposed children since the last contact investigation visit for a period of $\geq 2$ years after the exposure to identify TB cases diagnosed in the HUS area outside the contact investigations.

The Bacille Calmette-Guérin (BCG) vaccination status was classified from the medical records (i.e. vaccination chart, parent reported or BCG scar). Based on previous literature, we evaluated if the patient had any medical conditions considered to increased risk for progression to disease (e.g. HIV, malignancy or immunosuppressive therapy) [13]. We determined the contact tracing delay as the interval in days from the diagnosis of index case (i.e. first date of TB treatment) to the date of first TB contact investigation visit.

\section{Statistical analysis}

We used Mann-Whitney $U$ or Kruskal-Wallis and two-tailed Fisher's exact or chi-square tests for the comparison of continuous and categorical data, respectively. Binary logistic regression was used to examine potential risk factors for infection. Factors for univariate analysis (odds ratios, ORs) were selected based on previous literature [13]. Age, gender and factors with significant association were selected for multivariable analysis (adjusted odds ratios, aORs). Because of the known association between cavitary disease and sputum smear positivity, these factors were combined so that a reference group without cavitation and smear negative could be used in the multivariable model [14]. A $p$-value less than 0.05 was considered statistically significant. Data was 
analysed with SPSS Statistics (Version 24, IBM Corporation, Armonk, NY, US).

\section{Results}

There were 5092 listed TB contacts of whom 526 (10.3\%) were included to the data analysis together with their 121 index cases (Fig. 1). The characteristics, contact tracing delays and outcomes of the exposed children are presented in Table 1, and the characteristics of the index cases in Table 2.

Altogether, nine cases of TB disease and 25 cases of TB infection were diagnosed among the exposed children resulting in an overall contact investigation yield of $6.5 \%$ (34/526) for TB disease or infection. Outside the contact investigations, none of the exposed children were diagnosed with TB in the HUS area within $\geq 2$ years after the exposure. The characteristics and diagnostic test results of the exposed children with TB disease or infection are presented in supplementary Table 1 . The median age of the children with TB disease and infection was 10.9 years (interquartile range, IQR, 4.3-13.7 years) and 8.9 years (IQR, 3.9-12.9 years), respectively. None were identified to have a medical condition considered to increased risk for progression to disease. One child with disease (1/9) and six with infection (6/25) were diagnosed during follow-up after conversion of Tuberculin Skin Test (TST), Interferon-Gamma Release Assay (IGRA) or both. All of them were diagnosed within 4 months of the first contact investigation visit and none received preventive treatment before the diagnosis. Three of the cases diagnosed with infection during follow-up were under the age of five. At the time of diagnosis, the median TST results of the children with TB disease and infection were $18 \mathrm{~mm}$ (IQR, 8-19 mm) and $17 \mathrm{~mm}$ (IQR, 11-20 mm), respectively. None of the pTB cases were microbiologically confirmed. One child in the congregate exposure group had culture confirmed abdominal TB disease.

The maximum contact tracing delay for the children under 5 years of age with either TB disease or infections was 7 days among the household exposure group and 12 days among the other exposure group. None of the children with TB disease had severe disease forms such as meningeal or miliary disease. All made full recovery: 8/9 completed full TB treatment, and in one case, the treatment was discontinued slightly before full completion due to elevated liver enzymes. Among the exposed children with TB infection without disease, 22/25 completed full preventive treatment, one moved abroad during the treatment, and two with a multidrug resistant TB (MDR-TB) index case were followed up for over 2 years without preventive treatment or progression to disease.

The OR for TB disease or infection per exposure group is presented in Table 3. Due to low yield in the congregate exposure group, we excluded this group from further analysis.
The ORs per different factors among the household and other contacts are presented in Table 4. In the univariate analysis, household exposure, BCG vaccination and birth in a TB endemic country (incidence $\geq 50 / 100,000$ ) of the contact and smear positivity and pulmonary cavitation on chest $\mathrm{x}$-ray of the index case were associated with TB disease or infection of the exposed children. Because BCG likely reflects birth in a TB endemic country, it was excluded from the multivariable analysis. In the multivariable analysis, household exposure (aOR 2.96, 95\% confidence interval, CI 1.33-6.58) and birth in a TB endemic country (aOR 3.07, 95\% CI 1.10-8.57) of the contact and smear positivity (aOR 3.96, 95\% CI 1.20-13.03) of the index case were associated with TB disease or infection of the exposed children (Table 5).

\section{Discussion}

In our retrospective contact tracing cohort from low incidence settings, approximately $10 \%$ of all listed contacts were paediatric and $4 \%$ were at the most vulnerable age of under 5 years. The European consensus is that TB contacts should be informed within a week after identification of the index case and young children are a high priority in contact tracing [13]. Since young children are prone to rapid and severe disease, those with strong exposure should be evaluated urgently. Contact tracing in the HUS area identified exposed young children quickly: most of the TB infections among the children under 5 years of age were found before progression to disease and none had severe disease forms. Most children under 5 years of age in the household exposure group had first contact investigation visit within a week and the maximum delay for those with either TB disease or infection was 7 days. Our results show that prompt investigations and early diagnosis can be achieved with well-organised contact tracing structure.

Recent paediatric contact tracing publications from lowincidence European countries are scarce [4]. A large systematic review from high-income settings found that the prevalence of active TB and latent TB infection (LTBI) was $4.7 \%$ and $16.3 \%$ among children aged $\leq 5$ years and $2.9 \%$ and $18.4 \%$ among children aged 5-14 years, respectively [6]. However, the publications had substantial heterogeneity suggesting that the estimates might not be comparable with Europe. The epidemiological landscape in high-income European countries also varies: for example, in Croatia, the reported LBTI yield among close contacts under 5 years of age is much higher $26.4 \%$ [15]. In our study, the TB infection and disease yields among the exposed children under 5 years of age were much lower compared with the aforementioned figures. The relatively low yield in our study suggests that index cases in the HUS area are promptly diagnosed and isolated before transmission mostly occurs. The TB disease and 
Table 1 The characteristics, contact tracing delays and outcome of paediatric TB contacts exposed to TB in HUS area $2012-2016$.

\begin{tabular}{|c|c|c|c|c|c|c|c|}
\hline & & \multirow[t]{2}{*}{ Total } & \multicolumn{3}{|l|}{ Exposure group } & \multicolumn{2}{|c|}{ Difference between groups $(p)$} \\
\hline & & & Household (1) & Other (2) & Congregate (3) & 1 vs. 2 & 1 vs. 2 vs. 3 \\
\hline \multirow[t]{28}{*}{ Contact } & $N$ & 526 & $109(20.3)$ & $221(41.1)$ & $196(36.4)$ & N/A & $\mathrm{N} / \mathrm{A}$ \\
\hline & Age, years & & & & & 0.32 & $<0.0001$ \\
\hline & Median & 6.57 & 5.05 & 4.03 & 12.02 & & \\
\hline & IQR & $2.5-13.5$ & $2.2-10.8$ & $1.7-10.0$ & $4.0-14.3$ & & \\
\hline & Age group, years & & & & & 0.52 & $<0.0001$ \\
\hline & $<5$ & $224(42.6)$ & $51(46.8)$ & $118(53.4)$ & $55(28.1)$ & & \\
\hline & $5-9$ & $105(20.0)$ & $28(25.7)$ & $48(21.7)$ & $29(14.8)$ & & \\
\hline & $\geq 10$ & $197(37.5)$ & $30(27.5)$ & $55(24.9)$ & $112(57.1)$ & & \\
\hline & Sex & & & & & 0.77 & 0.03 \\
\hline & Male & $273(51.9)$ & $63(57.8)$ & $124(56.1)$ & $86(43.9)$ & & \\
\hline & Female & $249(47.3)$ & $46(42.2)$ & $98(44.1)$ & $105(53.8)$ & & \\
\hline & Unknown & $4(0.8)$ & 0 & 0 & $4(2.1)$ & & \\
\hline & Birth & & & & & 0.001 & $<0.0001$ \\
\hline & Native & $411(78.1)$ & $85(78.0)$ & $198(89.6)$ & $128(65.3)$ & & \\
\hline & Immigrant & $106(20.2)$ & $24(22.0)$ & $20(9.0)$ & $62(31.6)$ & & \\
\hline & TB endemic country ${ }^{\mathrm{a}}$ & $96(18.3)$ & $19(17.4)$ & $15(6.8)$ & $62(31.6)$ & 0.003 & $<0.0001$ \\
\hline & Unknown & $9(1.7)$ & 0 & $3(1.4)$ & $6(3.1)$ & & \\
\hline & $\mathrm{BCG}$ & & & & & $<0.0001$ & $<0.0001$ \\
\hline & Yes & $234(43.5)$ & $87(79.8)$ & $120(54.3)$ & $27(13.8)$ & & \\
\hline & Among $<5$ age group ${ }^{\mathrm{b}}$ & $92(48.7)$ & $41(80.4)$ & $43(40.2)$ & $8(25.8)$ & & \\
\hline & No & $121(23.0)$ & $16(14.7)$ & $77(34.8)$ & $28(14.3)$ & & \\
\hline & Unknown & $171(32.5)$ & $6(5.5)$ & $24(10.9)$ & $141(71.9)$ & & \\
\hline & Delay, days & & & & & & \\
\hline & Median & 18 & 10 & 14 & 30 & 0.02 & $<0.0001$ \\
\hline & IQR & $10-35$ & $4-19$ & $8-25$ & $22-42$ & & \\
\hline & $\leq 7$ days $^{\mathrm{b}}$ & $102(21.0)$ & $51(46.8)$ & $46(22.5)$ & $5(2.9)$ & 0.04 & $<0.0001$ \\
\hline & Among $<5$ age group ${ }^{\mathrm{b}}$ & $64(30.6)$ & $33(64.7)$ & $28(25.7)$ & $3(8.2)$ & & \\
\hline & Unknown & $41(7.8)$ & 0 & $17(7.7)$ & $24(12.2)$ & & \\
\hline \multirow[t]{10}{*}{ Index } & $N$ & 121 & 53 & 80 & 11 & N/A & N/A \\
\hline & Contacts/Index ratio & & & & & & \\
\hline & Median & 2 & 2 & 2 & 7 & N/A & N/A \\
\hline & Range & $1-94$ & $1-5$ & $1-14$ & $1-89$ & & \\
\hline & Relation to contact & & & & & $\mathrm{N} / \mathrm{A}$ & N/A \\
\hline & Parent & $61(11.6)$ & $56(51.4)$ & $5(2.3)$ & 0 & & \\
\hline & Sibling & $16(3.0)$ & $16(14.7)$ & 0 & 0 & & \\
\hline & Grandparent & $82(15.6)$ & $18(16.5)$ & $64(29.0)$ & 0 & & \\
\hline & Aunt/uncle & $35(6.7)$ & $7(6.4)$ & $28(12.7)$ & 0 & & \\
\hline & Other & $332(63.1)$ & $12(11.0)$ & $124(56.1)$ & $196(100.0)$ & & \\
\hline \multirow[t]{13}{*}{ Outcome } & $\mathrm{TB}$ disease or infection & $34(6.5)$ & $19(17.4)$ & $14(6.3)$ & $1(0.5)$ & 0.003 & $<0.0001$ \\
\hline & TB disease & $9(1.7)$ & $5(4.6)$ & $3(1.4)$ & $1(0.5)$ & 0.13 & 0.07 \\
\hline & $<5$ years & $3(1.3)$ & $2(3.9)$ & $1(0.8)$ & 0 & 0.22 & 0.19 \\
\hline & Immigrant & $5(4.7)$ & $4(16.7)$ & 0 & $1(1.6)$ & 0.11 & 0.02 \\
\hline & TB infection & $25(4.8)$ & $14(12.8)$ & $11(5.0)$ & 0 & 0.02 & $<0.0001$ \\
\hline & $<5$ years & $7(3.1)$ & $1(2.0)$ & $6(5.1)$ & 0 & 0.68 & 0.20 \\
\hline & Immigrant & $6(5.7)$ & $5(20.8)$ & $1(5.0)$ & 0 & 0.20 & $<0.001$ \\
\hline & No infection & $431(81.9)$ & $87(79.8)$ & $189(85.5)$ & $155(79.5)$ & & \\
\hline & Received prophylaxis & $41(7.8)$ & $14(12.8)$ & $26(11.8)$ & $1(0.5)$ & N/A & N/A \\
\hline & Unknown & $61(11.6)$ & $3(2.8)$ & $18(8.1)$ & $40(20.4)$ & & \\
\hline & Outside HUS ${ }^{\mathrm{c}}$ & $23(4.4)$ & 0 & $13(5.9)$ & $10(5.1)$ & & \\
\hline & Lost to follow-up & $36(6.8)$ & $3(2.8)$ & $5(2.3)$ & $28(14.4)$ & 0.99 & $<0.0001$ \\
\hline & No data & $2(0.4)$ & 0 & 0 & $2(1.0)$ & & \\
\hline
\end{tabular}

Note: Categorical data are $N(\%)$

$N / A$ not applicable, $B C G$ Bacille Calmette-Guérin vaccination, IQR interquartile range

${ }^{a}$ Born in a high TB incidence $(\geq 50 / 100,000)$ country

${ }^{\mathrm{b}}$ Percentage out of those with BCG or delay data available

${ }^{\mathrm{c}}$ Contact investigations outside the hospital district of Helsinki and Uusimaa 
Table 2 Characteristics of the index case and relation to the outcome of the paediatric contacts

\begin{tabular}{|c|c|c|c|c|}
\hline \multirow[t]{2}{*}{ Characteristic } & \multirow[t]{2}{*}{ Total } & \multicolumn{2}{|c|}{ Contacts with TB infection or disease } & \multirow[t]{2}{*}{ Difference $(p)$} \\
\hline & & $\geq 1$ & None & \\
\hline$N$ & 114 & $21(17.4)$ & $93(76.9)$ & N/A \\
\hline Age, years & & & & 0.21 \\
\hline Median & 39.8 & 38.5 & 40.7 & \\
\hline IQR & $27.8-65.3$ & $25.7-44.9$ & $28.8-66.4$ & \\
\hline Sex & & & & 0.99 \\
\hline Male & $63(55.3)$ & $12(57.1)$ & $51(54.8)$ & \\
\hline Female & $49(43.0)$ & $9(42.9)$ & $40(43.0)$ & \\
\hline Unknown & $2(1.7)$ & 0 & $2(2.2)$ & \\
\hline Birth & & & & 0.16 \\
\hline Native & $60(52.6)$ & $8(38.1)$ & $52(55.9)$ & \\
\hline Immigrant & $54(47.4)$ & $13(61.9)$ & $41(44.1)$ & \\
\hline TB focus & & & & 0.46 \\
\hline Pulmonary & $110(96.5)$ & $20(95.2)$ & $90(96.8)$ & \\
\hline Extrapulmonary & $3(2.6)$ & $1(4.8)$ & $2(2.2)$ & \\
\hline Unknown & $1(0.9)$ & 0 & $1(1.1)$ & \\
\hline Smear & & & & 0.01 \\
\hline Positive & $(59.6)$ & $17(81.0)$ & $51(54.8)$ & \\
\hline Negative & $45(39.5)$ & $3(14.3)$ & $42(45.2)$ & \\
\hline Unknown & $1(0.9)$ & $1(4.8)$ & 0 & \\
\hline Cavitation $^{\mathrm{a}}$ & & & & $<0.0001$ \\
\hline Yes & $29(25.4)$ & $14(66.7)$ & $15(16.1)$ & \\
\hline No & $82(71.9)$ & $7(33.3)$ & $75(80.6)$ & \\
\hline Unknown & $3(2.6)$ & 0 & $3(3.2)$ & \\
\hline MTB drug susceptibility & & & & $0.25^{\mathrm{b}}$ \\
\hline Sensitive & $94(82.5)$ & $17(81.0)$ & $77(82.8)$ & \\
\hline Resistant & $12(10.5)$ & $4(19.0)$ & $8(8.6)$ & \\
\hline Mono resistant & $7(6.1)$ & $2(9.5)$ & $5(5.4)$ & \\
\hline MDR & $4(3.5)$ & $2(9.5)$ & $2(2.2)$ & \\
\hline $\mathrm{XDR}$ & $1(0.9)$ & 0 & $1(1.1)$ & \\
\hline Unknown & $8(7.0)$ & 0 & $8(8.6)$ & \\
\hline
\end{tabular}

Note: Data on seven index cases with all contact outcomes unknown not presented. Categorical data are $N(\%)$ N/A not applicable, IQR interquartile range, MTB Mycobacterium tuberculosis, MDR multidrug-resistant, XDR extensively drug-resistant

${ }^{\text {a }}$ Cavitation on chest radiograph

${ }^{\mathrm{b}}$ Sensitive vs. resistant

infection yields among all paediatric household contacts in our study $(4.6 \%$ and $12.8 \%)$ compare relatively well with those reported from a cohort of children under 18 years of age in Sweden (3.5\% and 17.1\%) [16]. Similar LTBI yield $(13.1 \%)$ has also been reported from France among children under 15 years of age with closed room exposure time over $40 \mathrm{~h}$, although TB disease was found less frequently in the French cohort (1.4\%) [17]. LTBI was slightly less frequent among exposed children under 15 years of age in the UK (10\%) and household contacts under 16 years of age in Germany $(4.5 \%$ or $9 \%$ depending on the TST cut-off) $[18,19]$.
As in previous studies, the risk for TB infection or disease was higher among children with household exposure and a sputum smear positive index case $[16,17,20]$. Similar to Sweden, the risk was also higher among children born in a TB endemic country [16]. Close-contact investigations among immigrant population have been shown to be cost-effective, although foreign-born contacts are more likely to remain unidentified [21, 22]. It is likely that investigations among the immigrant community identify also old infections resulting from TB exposure abroad. In Finland, LTBI screening is only performed as a pre-BCG-immunisation investigation and approximately $20 \%$ of all immigrant TB cases are diagnosed 
Fig. 1 Flowchart of data collection and the annual number of contacts by exposure

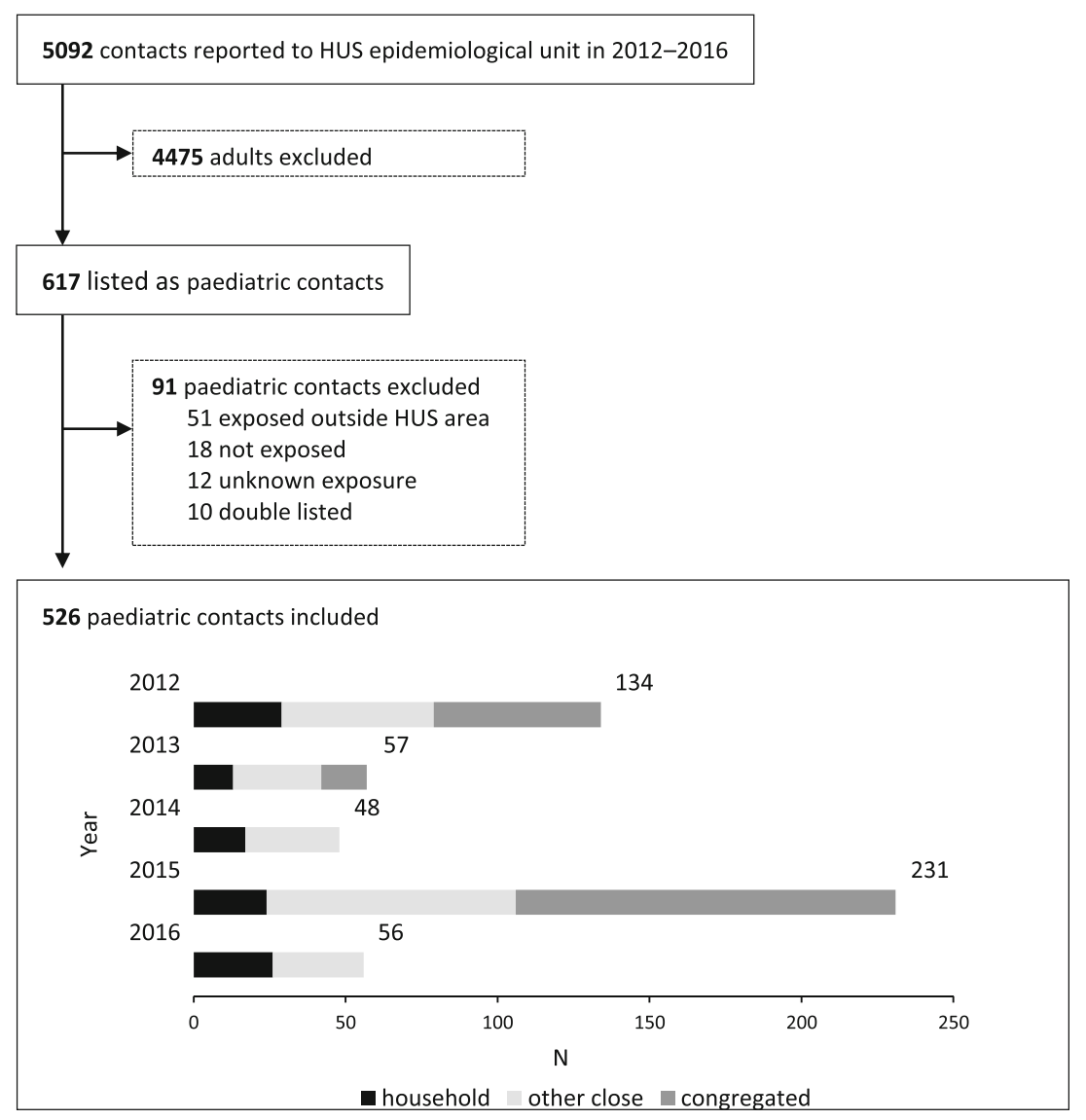

through TB screening [23]. The date of entry or TB screening data for the immigrant cases in our study was not available. However, besides capturing TB disease early, the prompt investigations among the exposed immigrant children provided important baseline test results: 7/11 had active disease or exhibited TST and/or IGRA conversion suggesting a recent infection. Nevertheless, a more active case-detection approach among high-risk immigrant children warrants further evaluation.

The yield in the congregate exposure group was very low: the large-scale investigations among those exposed in congregate setting were mostly inefficient. We also suspect that the only TB case was coincidental and likely not related to the congregate exposure. In our national guidelines, the exposure criteria for TB investigations were essentially the same for all out-of-household contacts. Thus, it seems that the exposure

Table 3 Unadjusted odds ratios for $\mathrm{TB}$ disease or infection among paediatric tuberculosis contacts according to exposure group

\begin{tabular}{lll}
\hline & OR & $95 \% \mathrm{CI}$ \\
\hline Exposure & & \\
Household & 1.00 & - \\
Other & 0.34 & $0.16-0.71$ \\
Congregate & 0.03 & $0.004-0.22$ \\
\hline \multicolumn{2}{l}{ OR odds ratio, $C$ CI confidence interval }
\end{tabular}

risk in congregate settings is difficult to quantify and may be overestimated. Nevertheless, molecular epidemiological studies have shown that TB transmission can occur through social exposure and large school outbreaks of TB have been reported

Table 4 Unadjusted odds ratios for TB disease or infection among household and other paediatric contacts according to the different factors

\begin{tabular}{llll}
\hline & & OR & $95 \%$ CI \\
\hline Exposure & Household & 2.95 & $1.41-6.15$ \\
Contact & Age group, years & & \\
& $5-9$ & 1.00 & - \\
& $<5$ & 0.53 & $0.20-1.40$ \\
& $\geq 10$ & 1.85 & $0.73-4.66$ \\
& Gender, male & 0.67 & $0.33-1.39$ \\
& BCG, yes & 4.48 & $1.32-15.15$ \\
& TB endemic country & \\
& Age, years & 4.09 & $1.70-9.84$ \\
& Gender, male & 0.99 & $0.97-1.01$ \\
& Smear, positive & 0.94 & $0.45-1.95$ \\
& Cavity, yes & 2.99 & $1.12-8.02$ \\
& & 4.06 & $1.91-8.63$ \\
\hline
\end{tabular}

Bold indicates statistically significant factor in logistic regression $O R$ odds ratio, $C I$ confidence interval

${ }^{\mathrm{a}}$ Immigrant born in a high TB incidence country $(\geq 50 / 100,000)$ 
Table 5 Adjusted odds ratios for TB disease or infection among paediatric contacts according to the different factors

\begin{tabular}{llll}
\hline & & aOR & CI \\
\hline $\begin{array}{lll}\text { Exposure } \\
\text { Contact }\end{array}$ & Household & 2.96 & $1.33-6.58$ \\
& Age group, years & & \\
& $5-9$ & 1.0 & - \\
& $<5$ & 0.96 & $0.34-2.73$ \\
& $\geq 10$ & 1.69 & $0.63-4.566$ \\
& Gender, male & 0.67 & $0.31-1.47$ \\
& TB endemic country & 3.07 & $1.10-8.57$ \\
Index & Infectivity & & \\
& $\quad$ Smear-/cavitation- & 1.0 & - \\
& $\quad$ Smear+ & 3.96 & $1.20-13.03$ \\
& $\quad$ Smear-/cavitation+ & 1.52 & $0.15-15.83$ \\
\hline
\end{tabular}

Bold indicates statistically significant factor in multiple logistic regression

$a O R$ adjusted odds ratio, $\mathrm{CI}$ confidence interval

${ }^{a}$ Immigrant born in a high TB incidence country $(\geq 50 / 100,000)$

$[24,25]$. Infections or the lack of them among those with the highest presumed risk can provide empirical evidence of the true infectiousness of the index case. Fruitless large-scale investigations deplete valuable contact tracing resources and might be avoided with a more cautious and targeted initial approach.

Since 2006, only children considered to have high TB exposure risk have been BCG vaccinated in Finland. Children undergoing contact investigations have evidently been at risk for TB exposure. Thus, optimally, all exposed children should have been BCG vaccinated. In Finland, majority of TB cases still occur among the older indigenous population, and TB exposure from grandparents was substantial [26]. Most of the exposed children under 5 years of age with a grandparent as an index case were non-BCG-vaccinated suggesting that this risk group of grandchildren is not comprehensively captured under the current selective BCG policy. The relatively high proportion of non-BCG-vaccinated children further emphasises the need for a rapid and effective contact tracing protocol.

\section{Limitations}

Our retrospective study holds some limitations and results should be viewed with caution. The infectiousness of the index case and level of exposure were based on available retrospective data. Index cases were based on the epidemiological link and not molecular epidemiology, and some of the infections might be from another source. Data concerning unidentified contacts and enabling cost-benefit analysis was not available. An important factor contributing to the total delay of children exposed to TB is the diagnostic delay of the index case which was not covered in our study.

\section{Conclusion}

Vulnerable young children should be evaluated as soon as possible after TB exposure. Prompt investigations and early diagnosis can be achieved with a well-organised contact tracing structure. Large-scale investigations after TB exposure in a congregate setting can result in a very low yield. Thus, TB investigations after such exposure should be cautiously targeted. TB disease or infection risk was higher among the children born in a TB endemic country. Timely investigations enabled identification of IGRA and TST conversions, and most immigrant cases were likely recent infections. In a risk group-based BCG vaccination policy, children with TB exposure risk from grandparents are difficult to identify for immunisation.

Supplementary Information The online version contains supplementary material available at https://doi.org/10.1007/s00431-021-04000-7.

\section{Code availability N/A}

Author contribution A.K., S.K., E.R. and E.S. conceived and designed the study. A.K. and S.K. collected the data. A.K. performed the data analysis. A.K., S.K., E.R. and E.S. wrote the paper.

Funding Open access funding provided by University of Helsinki including Helsinki University Central Hospital. This work was supported by the Foundation of the Finnish Anti-Tuberculosis Association, Päivikki and Sakari Sohlberg Foundation, and Väinö and Laina Kivi Foundation.

Data availability The data are not publicly available due to restrictions.

\section{Declarations}

Ethics approval The ethics approval for the study was given by the Research Ethical Committee of the HUS.

Consent to participate N/A

Consent for publication N/A

Conflict of interest The authors declare that they have no conflict of interest.

Open Access This article is licensed under a Creative Commons Attribution 4.0 International License, which permits use, sharing, adaptation, distribution and reproduction in any medium or format, as long as you give appropriate credit to the original author(s) and the source, provide a link to the Creative Commons licence, and indicate if changes were made. The images or other third party material in this article are included 
in the article's Creative Commons licence, unless indicated otherwise in a credit line to the material. If material is not included in the article's Creative Commons licence and your intended use is not permitted by statutory regulation or exceeds the permitted use, you will need to obtain permission directly from the copyright holder. To view a copy of this licence, visit http://creativecommons.org/licenses/by/4.0/.

\section{References}

1. Raisanen PE, Soini H, Vasankari T et al (2016) Tuberculosis in immigrants in Finland, 1995-2013. Epidemiol Infect 144(2):425433

2. Grzybowski S, Barnett GD, Styblo K (1975) Contacts of cases of active pulmonary tuberculosis. Bull Int Union Tuberc 50(1):90106

3. Perez-Velez CM, Marais BJ (2012) Tuberculosis in children. N Engl J Med 367(4):348-361

4. Martinez L, Cords O, Horsburgh CR, Andrews JR, Pediatric TBCSC (2020) The risk of tuberculosis in children after close exposure: a systematic review and individual-participant meta-analysis. Lancet 395(10228):973-984

5. Sloot R, Schim van der Loeff MF, Kouw PM, Borgdorff MW (2014) Risk of tuberculosis after recent exposure. A 10-year follow-up study of contacts in Amsterdam. Am J Respir Crit Care Med 190(9):1044-1052

6. Fox GJ, Barry SE, Britton WJ, Marks GB (2013) Contact investigation for tuberculosis: a systematic review and meta-analysis. Eur Respir J 41(1):140-156

7. (2012) Recommendations for investigating contacts of persons with infectious tuberculosis in low- and middle-income countries. Geneva, World Health Organization

8. Lonnroth K, Migliori GB, Abubakar I et al (2015) Towards tuberculosis elimination: an action framework for low-incidence countries. Eur Respir J 45(4):928-952

9. Tebruegge M, Salo E, Ritz N, Kampmann B (2013) The Paediatric Tuberculosis Network European Trialsgroup P. Inclusion of latent tuberculosis infection as a separate entity into the international classification of diseases. Thorax 68(6):588

10. Borgen K, Koster B, Meijer H, Kuyvenhoven V, van der Sande M, Cobelens F (2008) Evaluation of a large-scale tuberculosis contact investigation in the Netherlands. Eur Respir J 32(2):419-425

11. (referred 21 November 2019) Access method: https://www.hus.fi/ hus-tietoa/husn-tunnuslukuja/Sivut/default.aspx

12. National Infectious Diseases Register: Tuberculosis [e-publication]. Helsinki: National Institute for Health and Welfare. (referred November 21, 2019) Access method: https://thl.fi/ttr/gen/rpt/ tilastot.htmlhttps://thl.fi/ttr/gen/rpt/tilastot.html

13. Erkens CG, Kamphorst M, Abubakar I et al (2010) Tuberculosis contact investigation in low prevalence countries: a European consensus. Eur Respir J 36(4):925-949

14. Palaci M, Dietze R, Hadad DJ, Ribeiro FKC, Peres RL, Vinhas SA, Maciel ELN, do Valle Dettoni V, Horter L, Boom WH, Johnson JL,
Eisenach KD (2007) Cavitary disease and quantitative sputum bacillary load in cases of pulmonary tuberculosis. J Clin Microbiol 45(12):4064-4066

15. Pavic I, Topic RZ, Raos M, Aberle N, Dodig S (2011) Interferongamma release assay for the diagnosis of latent tuberculosis in children younger than 5 years of age. Pediatr Infect Dis J 30(10): 866-870

16. Bennet R, Nejat S, Eriksson M (2020) Foreign background and older age of children were associated with infection in Swedish tuberculosis contacts. Acta Paediatr 109(9):1854-1859

17. Aissa K, Madhi F, Ronsin N, Delarocque F, Lecuyer A, Decludt B, Remus N, Abel L, Poirier C, Delacourt C, CG94 Study Group (2008) Evaluation of a model for efficient screening of tuberculosis contact subjects. Am J Respir Crit Care Med 177(9):1041-1047

18. Cavany SM, Sumner T, Vynnycky E, Flach C, White RG, Thomas HL, Maguire H, Anderson C (2017) An evaluation of tuberculosis contact investigations against national standards. Thorax 72(8): 736-745

19. Diel R, Loddenkemper R, Meywald-Walter K, Niemann S, Nienhaus A (2008) Predictive value of a whole blood IFNgamma assay for the development of active tuberculosis disease after recent infection with Mycobacterium tuberculosis. Am J Respir Crit Care Med 177(10):1164-1170

20. Marks SM, Taylor Z, Qualls NL, Shrestha-Kuwahara RJ, Wilce MA, Nguyen CH (2000) Outcomes of contact investigations of infectious tuberculosis patients. Am J Respir Crit Care Med 162(6):2033-2038

21. Borraccino A, Migliore E, Piccioni P, Baussano I, Carosso A, Bugiani M (2014) Yield of tuberculosis contact investigation in a low-incidence country. J Infect 68(5):448-454

22. Dasgupta K, Schwartzman K, Marchand R, Tennenbaum TN, Brassard P, Menzies D (2000) Comparison of cost-effectiveness of tuberculosis screening of close contacts and foreign-born populations. Am J Respir Crit Care Med 162(6):2079-2086

23. Raisanen PE, Soini H, Turtiainen P et al (2018) Enhanced surveillance for tuberculosis among foreign-born persons, Finland, 20142016. BMC Public Health 18(1):610

24. Hoskyns W (2003) Paediatric tuberculosis. Postgrad Med J 79(931):272-278

25. Smit PW, Vasankari T, Aaltonen H, Haanperä M, Casali N, Marttila H, Marttila J, Ojanen P, Ruohola A, Ruutu P, Drobniewski F, Lyytikäinen O, Soini H (2015) Enhanced tuberculosis outbreak investigation using whole genome sequencing and IGRA. Eur Respir J 45(1):276-279

26. Smit PW, Haanpera M, Rantala P et al (2014) Genotypic characterization and historical perspective of Mycobacterium tuberculosis among older and younger Finns, 2008-2011. Clin Microbiol Infect 20(11):1134-1139

Publisher's Note Springer Nature remains neutral with regard to jurisdictional claims in published maps and institutional affiliations. 